\title{
Thin Layer Chromatographic Analyses of Pesticides in a Soil Ecosystem
}

\author{
S. Afful ${ }^{1 *}$, S. A. Dogbe ${ }^{1}$, K. Ahmad ${ }^{1}$ and A. T. Ewusie ${ }^{2}$ \\ ${ }^{1}$ Department of Chemistry, NNRI/GAEC, Box LG. 80, Legon-Accra, Ghana \\ ${ }^{2}$ Department of Animal Science, GAEC, Box LG. 80, Legon-Accra, Ghana \\ *Corresponding author; E- mail: affulsammy@yahoo.com
}

\begin{abstract}
Silica gel 60, silica gel $60 \mathrm{~F}_{254}$, and aluminium oxide as adsorbents were used to investigate their suitability for the analysis and detection of the pesticides: nitrofen, atrazine, diuron, dioxacarb, propoxur, propanil, carbaryl and cypermethrin in soil ecosystem using ethyl acetate, chloroform, dichloromethane and ethyl acetate/chloroform (1:1) as developing solvents. O-tolidine and potassium iodide reagent were used for the detection of the pesticides. $R_{f}$ values obtained for the pesticides using the silica gel 60-ethyl acetate, silica gel $60 \mathrm{~F}_{254}$-ethyl acetate, silica gel 60-chloroform, silica gel $60 \mathrm{~F}_{254}$-chloroform, silica gel 60 - (1:1) ethyl acetate/chloroform and silica gel $60 \mathrm{~F}_{254}-(1: 1)$ ethyl acetate/chloroform systems generally were within the stipulated range of $0.4-0.8 . \mathrm{R}_{\mathrm{f}}$ values obtained for the pesticides using silica gel 60-dichloromethane and silica gel $60 \mathrm{~F}_{254}$-dichloromethane systems were very low except for cypermethrin and nitrofen. Analysis with aluminium oxide coated plates gave a heavy yellow background with the detection reagent making visualization of spots difficult. Aluminium oxide coated plate is, therefore, not recommended when o-tolidine plus potassium iodide is used as detection reagent.
\end{abstract}

\section{Introduction}

Pesticides are chemicals that are pest-killing agents. The term usually refers to one or more materials developed and used to destroy broad range of specific pests. In legal terminology, pesticides may be defined as substances used for controlling, preventing, destroying, repelling, or mitigating any pest. Hence, even chemicals that do not actually kill pests may, for practical and legal reasons, be considered pesticides (Ware, 1983). The problem of pest, particularly in agriculture, has made the use of pesticide very important, and, all over the world, pesticide products are being used to fight the problem of pests. The situation in Ghana, with respect to the used of pesticides, is not different, and, today, different pesticides products, ranging from insecticides, fungicides, herbicides, pyrethroids, etc., are imported and used for commercial production of food and cash crops such as cocoa, maize, coffee, rice, pineapples, cabbage, banana, and many others (Gerken et al., 2001).

In spite of the efficacy of many of these pesticide products in killing the target pests, other useful organisms are killed as a result of their usage. Many of the chemicals have long half-life and, as such, they tend to persist on the field after application. Residues of pesticides left on the field are, thus, washed by run-off into nearby streams and some even seepage into ground waters. Residues of pesticide in food crops have always been a burden confronting agronomists and environmentalists. It is against this background that determination of the quality of pesticide products before allowing them unto the market, and determination of residue level of the pesticides after application becomes very important.

Determination of pesticide residues usually involves the use of a form of chromatography. The most important chromatographic techniques for pesticide residues studies are gas chromatography (GC), high performance liquid chromato-graphy (HPLC) and thin layer chromato-graphy (TLC). Spectrophotometry could also be used for many pesticides, and calorimetric kits are available for choresterase inhibiting insecticides and fungicides (Afful, 2002). With the advent of GC and HPLC, the use of TLC for the quantitative determination of pesticide residues is becoming less popular. However, for screening and identification purposes it is still being used in many laboratories (Yeboah et al., 2003). It must be emphasized that the technique had been used for analysis of pesticide residues in soils (Ramasamy, 1969), plants and vegetables (Yeboah et al., 2002) and water (Abbot et al., 1965). Nevertheless, TLC will continue to be used in pesticide residual studies because of its simplicity, versatility and reduced need for sample clean up (Ambrus, 1986). 
Thin layer chromatography is analogous to other adsorptive techniques. An adsorbent, such as silica gel, aluminium oxide or cellulose is coated on a TLC plate. Commercially prepared TLC plates are also available on the market. A drop of the sample being analyzed is applied at the origin of the TLC plate using a micro syringe or capillary tube. The plate is placed in a developing chamber containing a solvent that act as a mobile phase. As the solvent migrates along the plate, it carries the components of the sample mixture along. A continuous adsorption-elution process takes place, and the most mobile component travel fastest, causing a complex mixture of the compounds to be resolved into series of spots. The selection of adsorbent-solvent system for TLC analysis is very critical to obtain the desired result. The location of the sample spot on a chromatogram is an index to the chemical nature and provides a guide for identifying the compounds separated. The migration of a spot on a chromatogram is usually expressed as retention factor $\left(\mathrm{R}_{\mathrm{f}}\right)$, which is expressed mathematically as:

$\mathrm{R}_{\mathrm{f}}=$ Distance of centre of spot from the origin

Distance solvent front from the origin

An ideal adsorbent-solvent system results in resolution when the retention factor $\left(\mathrm{R}_{\mathrm{f}}\right)$, is about $0.4-$ 0.8 (Kircher, 1967).

In the study, the retention factor $\left(\mathrm{R}_{\mathrm{f}}\right)$ of some pesticides applied to soil matrix were determined using 10 different adsorbent-solvent systems to ascertain the suitability of the TLC systems for analysis and detection of the pesticides. O-tolidine plus potassium iodide reagent were used as the detection reagent. These pesticides were selected because they are among the commonly used pesticides in Ghana.

Chemical and reagents

\section{Materials and methods}

The pesticides reference standards were obtained from Dr Ehrenstorfeer Gmbh, Darmstadt. The purity of the pesticide standards ranges from 97-99\% and were used without further purification. The TLC plates were already made and they were bought from Merck, Darmstadt, Germany. The plates were silica-gel or aluminium oxide coated. Pesticide standards $(1 \mathrm{mg} / \mathrm{ml})$ were prepared by dissolving $0.1 \mathrm{~g}$ of the standard in $1000 \mathrm{ml}$ of acetone. The stock solutions were diluted ten fold and used as working solutions. O-tolidine plus potassium iodide (oTKI) detection reagent were prepared by dissolving $0.5 \mathrm{~g}$ of 0 -tolidine in $10 \mathrm{ml}$ of acetic acid and thoroughly mixed with $2 \mathrm{~g}$ KI dissolved in $10 \mathrm{ml}$ distilled water, and the resultant solution diluted to $500 \mathrm{ml}$ with distilled water.

\section{Soil sampling}

Soil samples for the investigation were taken from a field at Ghana Atomic Energy Commission farm. The soil samples collected were each wrapped in aluminium foil and put together in black polyethylene bag. The samples were sieved through 2-mm mesh size sieve to remove stones and other debris. The samples were then air-dried and used for analysis.

\section{Soil spiking and extraction}

About $5 \mathrm{~g}$ of the soil sample was accurately weighed into $200 \mathrm{ml}$ extraction flask. The soil was then spiked with $2 \mathrm{ml}$ of $100 \mu \mathrm{g} / \mathrm{ml}$ of a particular pesticide standard solution to generate a concentration of $40 \mu \mathrm{g} / \mathrm{g}$. The extraction flask and its content were allowed to stay for $60 \mathrm{~min}$. Extraction was then performed by adding acetone/hexane (1:1) into the extraction flask and shaking the mixture on flask shaker for $2 \mathrm{~h}$. Filtration of the mixture was carried out using Whatman No. 42 filter paper. The filtrate obtained was cleaned on SPE cartridge, equipped with C-18 as adsorbent, which was earlier preconditioned with $2 \mathrm{ml}$ acetone/water (1:9). The cartridge and its content were dried for $15 \mathrm{~min}$ by vacuum pump and the pesticide eluted with $5 \mathrm{ml}$ acetone. The cleaned up extract was adjusted to $5 \mathrm{ml}$ with acetone and this was used for analysis. The procedures were repeated for the other pesticides. Control experiments (without the pesticides) were also set up. The control samples were also subjected to the same extraction procedure. 
Chromatographic analyses of the soil extracts

The already made silica gel 60, silica gel $60 \mathrm{~F}_{254}$ and Aluminium oxide-coated TLC plates were activated in an oven at $105{ }^{\circ} \mathrm{C}$ for $30 \mathrm{~min}$, and spotting of the plates were done manually with $1 \mu \mathrm{l}$ micro-syringe, and for each soil extract a total of $5 \mu$ l was dispensed on the TLC plate. The spotted TLC plates were developed in $22.5 \times 21.5 \times 6.5 \mathrm{~cm}^{3}$ tank which had been saturated with the development solvent. The eluent was allowed to rise to about $12 \pm 0.5 \mathrm{~cm}$ from the origin of the plates and the eluting layer dried in a fume hood.

The developed, dried TLC plate was placed in a tank, which had been saturated with chlorine vapour for $1 \mathrm{~min}$. The chlorine vapour was made by placing a 50-ml beaker containing about $1 \mathrm{~g}$ potassium perman-ganate at the bottom of an empty TLC tank and adding $10 \mathrm{ml}$ of concentrated $\mathrm{HCl}$ to the permanganate. Excess chlorine on the plate, after chlorination, was removed from the plate in a fume hood, after which spots were detected by spraying the plate with the detection reagent. Distances moved by solvent and spots were measured and these were used to calculate $R_{f}$ of the pesticides. Triplicate determination was made for each extract. The control extracts were also analyzed in the same way.

Spots obtained for the pesticides.

\section{Results and discussion}

When the developed plates were treated or sprayed with the detection reagent, blue-black spots were obtained with whitish background. Most spots stayed over night before disappearing. However, in the case of aluminium oxide coated plates heavy yellowish background resulted on spraying the plates with the detection reagent. The background was so heavy that detection of spots was difficult. The few spots detected were brown in colour (Table 5). Fig. 1 shows the chromatogram of the pesticides using silica gel 60-ethyl acetate adsorbent-solvent systems.

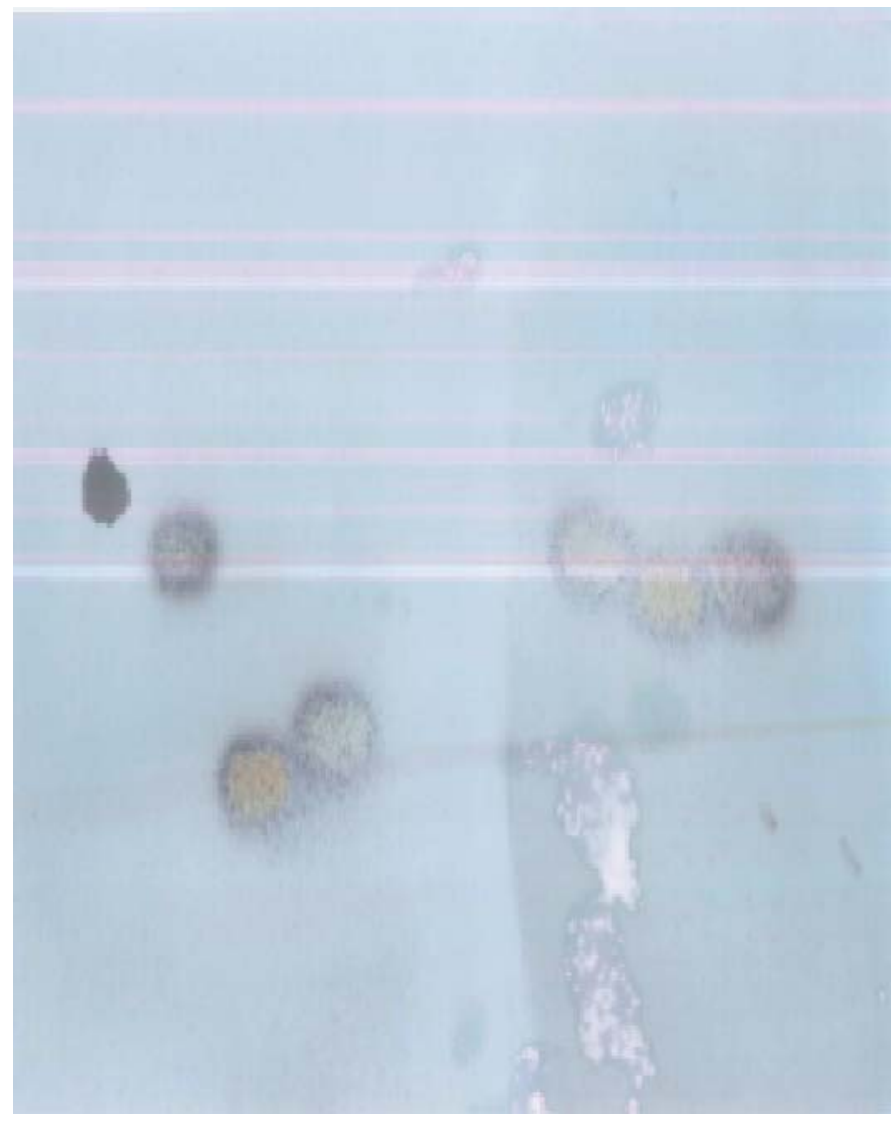


Fig. 1. Chromatogram obtained for the pesticides using silica gel 60 - ethy acetate system. From left to right are spots of nitrofen, atrazine, diuron, dioxacarb, propanil, propoxur and carbaryl. Cypermethrin was spotted between dioxacarb and propanil but not detected.

TLC analysis

TLC analysis of the extracts showed only one spot detected for all the sample extracts and, in each case, corresponded to the pesticide being investigated as the $R_{f}$ measured for each extract corresponded well with that of the standard pesticide solution analyzed concurrently. In the case of extracts from the control samples no spots were detected, which confirmed that the spots detected were that of the pesticides being investigated.

\section{$R_{f}$ data of the pesticides}

The $R_{f}$ data of the pesticides for the various adsorbent-solvent systems used for the investigation are presented in Tables 1, 2, 3, 4 and 5. Values in parenthesis are literature values (Yeboah et al., 2003). Margins of error are standard deviation, which were calculated based on triplicate measurement of each pesticide.

TABLE 1

$R_{f}$ of the pesticides, using silica gel-ethyl acetate adsorbent-solvent system

$\begin{array}{lcc}\text { Pesticides } & \begin{array}{c}\text { Silica gel } 60 R_{f} \text { (mean of three } \\ \text { replicates) }\end{array} & \begin{array}{c}\text { Silica gel } 60 F_{254} R_{f} \text { (mean of } \\ \text { three replicates) }\end{array} \\ \text { Nitrofen } & 0.70 \pm 0.03(0.68) & 0.71 \pm 0.04 \\ \text { Atrazine } & 0.64 \pm 0.04(0.62) & 0.66 \pm 0.04 \\ \text { Diuron } & 0.48 \pm 0.05(0.43) & 0.50 \pm 0.03 \\ \text { Dioxacarb } & 0.46 \pm 0.04(0.46) & 0.54 \pm 0.02 \\ \text { Propoxur } & 0.60 \pm 0.03(0.57) & 0.65 \pm 0.02 \\ \text { Propanil } & 0.62 \pm 0.02(0.57) & 0.64 \pm 0.02 \\ \text { Carbaryl } & 0.60 \pm 0.02(0.02) & 0.66 \pm 0.01 \\ \text { Cypermethrin } & \text { nd } & 0.75 \pm 0.01\end{array}$

TABLE 2

$R_{f}$ of the pesticides using silica gel - chloroform system

\begin{tabular}{|c|c|c|}
\hline Pesticides & $\begin{array}{c}\text { Silica gel } 60 \\
R_{f} \text { (mean of three replicates) }\end{array}$ & $\begin{array}{c}\text { Silica gel } 60 F_{254} \\
R_{f} \text { (mean of three replicates) }\end{array}$ \\
\hline Nitrofen & $0.72 \pm 0.05$ & $0.72 \pm 0.03$ \\
\hline Atrazine & $0.41 \pm 0.01$ & $0.40 \pm 0.03$ \\
\hline Diuron & $0.27 \pm 0.04$ & $0.32 \pm 0.04$ \\
\hline Dioxacarb & $0.21 \pm 0.04$ & $0.26 \pm 0.02$ \\
\hline Propoxur & $0.39 \pm 0.05$ & $0.45 \pm 0.02$ \\
\hline Propanil & $0.32 \pm 0.01$ & $0.40 \pm 0 / 05$ \\
\hline Carbaryl & $0.39 \pm 0.03$ & $0.48 \pm 0.02$ \\
\hline \multirow[t]{2}{*}{ Cypermethrin } & $0.72 \pm 0.02$ & $0.74 \pm 0.04$ \\
\hline & \multicolumn{2}{|c|}{$\begin{array}{l}\text { TABLE } 3 \\
\text { g silica gel-dichloromethane system }\end{array}$} \\
\hline \multirow[t]{2}{*}{ Pesticide } & Silica gel 60 & Silica gel $60 F_{254}$ \\
\hline & $R_{f}$ (mean of three replicates) & $R_{f}$ (mean of three replicates) \\
\hline Nitrofen & $0.74 \pm 0.05(0.66)$ & $0.77 \pm 0.04$ \\
\hline Atrazine & $0.08 \pm 0.01(0.06)$ & $0.14 \pm 0.03$ \\
\hline Diuron & $0.09 \pm 0.01(0.08)$ & $0.29 \pm 0.04$ \\
\hline Dioxacarb & $0.05 \pm 0.02(0.04)$ & $0.09 \pm 0.01$ \\
\hline Propoxur & $0.16 \pm 0.03(0.13)$ & $0.35 \pm 0.05$ \\
\hline Propanil & $0.27 \pm 0.04(0.27)$ & $0.28 \pm 0.03$ \\
\hline Carbaryl & $0.29 \pm 0.01(0.23)$ & $0.30 \pm 0.02$ \\
\hline
\end{tabular}

West African Journal of Applied Ecology, vol. 14, 2008 
TABLE 4

$$
R_{f} \text { of the pesticides in using silica gel-(1:1) ethyl acetate/chloroform system }
$$

$\begin{array}{lcr}\text { Pesticide } & \begin{array}{c}\text { Silica gel } 60 \\ R_{f} \text { (mean of three replicates) }\end{array} & \begin{array}{r}\text { Silica gel } 60 \mathrm{~F} \\ R_{f} \text { (mean of three rep }\end{array} \\ \text { Nitrofen } & 0.75 \pm 0.01 & 0.82 \pm 0.05 \\ \text { Atrazine } & 0.64 \pm 0.03 & 0.69 \pm 0.04 \\ \text { Diuron } & 0.48 \pm 0.03 & 0.56 \pm 0.05 \\ \text { Dioxacarb } & 0.42 \pm 0.03 & 0.51 \pm 0.04 \\ \text { Propoxur } & 0.59 \pm 0.01 & 0.69 \pm 0.03 \\ \text { Propanil } & 0.58 \pm 0.01 & 0.69 \pm 0.04 \\ \text { Carbaryl } & 0.57 \pm 0.02 & 0.71 \pm 0.05 \\ \text { Cypermethrin } & 0.69 \pm 0.04 & 0.84 \pm 0.05\end{array}$

TABLE 5

$R_{f}$ of the pesticides using aluminium oxide- ethyl acetate and aluminium oxide -dichloromethane system

$\begin{array}{lcc}\text { Pesticide } & \begin{array}{c}\text { Aluminium oxide-ethyl acetate } \\ R_{f} \text { (mean of three replicates) }\end{array} & \begin{array}{c}\text { Aluminium oxide-dichloromethane } \\ R_{f} \text { (mean of three replicates) }\end{array} \\ \text { Nitrofen } & 0.76 \pm 0.02 & 0.84 \pm 0.02^{*} \\ \text { Atrazine } & \text { nd } & \\ \text { Diuron } & 0.61 \pm 0.01 & \text { nd } \\ \text { Dioxacarb } & \text { nd } & \text { nd } \\ \text { Propoxur } & \text { nd } & \text { nd } \\ \text { Propanil } & 0.65 \pm 0.04 & \text { nd } \\ \text { Carbaryl } & 0.68 \pm 0.03 & \text { nd } \\ \text { Cypermethrin } & \text { nd } & \text { nd }\end{array}$

*Spot detected one day after spraying the plates with the detection reagent.

The silica gel-ethyl acetate systems (Table 1 ) gave $R_{f}$ spread in the range of $0.46-0.75$. It is of interest to observe that $R_{f}$ values obtained for the silica gel $60 \mathrm{~F}_{254}$ adsorbent were quite higher than those of silica gel 60, showing a higher affinity between the pesticides and the silica gel 60 stationary phase, compared to the silica gel $60 \mathrm{~F}_{254}$ stationary phase. Though cypermethrin was detected with the silica gel $60 \mathrm{~F}_{254}$-ethyl acetate system, the chemical was not detected at all using the silica gel 60-ethyl acetate elution system (Table 1). This observation could have come from the difference in compositions of the two adsorbents. From the results presented it is clear that for a multi residue analysis involving a mixture of atrazine, propoxur, propanil and carbaryl, this adsorbent-solvent systems could not be useful for their analysis since their $R_{f}$ values are close. This means that their spots would overlap and resolution would be impossible. However, for a sample which contains only one of the chemicals, these TLC systems could be used.

The pesticides in the silica gel-chloroform system (Table 2) gave spread of $R_{f}$ values ranging from 0.21 to 0.74 . The low $R_{f}$ values obtained for atrazine, diuron, dioxacarb, propoxur, propanil and carbaryl indicate that their ascent on the adsorbent were retarded by their relative insolubility in the mobile phase, and, probably, their tendency to be adsorbed onto the stationary phase. The high $R_{f}$ values for nitrofen and cypermethrin rather imply their high solubility in the mobile phase.

In the case of the silica gel-dichloro-methane systems (Table 3), all the chemicals, with the exception of nitrofen and cypermethrin, gave very low $R_{f}$ values; those of atrazine and diuron were comparatively very low. Values obtained, however, compare favourably with reported values 
(Yeboah et al., 2003). The lower $R_{f}$ values mean that the pesticides moved very little from the origin, an indication of unsuitability of these TLC systems for analysis and detection of the pesticides. In a multi residue analysis involving nitrofen and cypermethrin the silica gel $60 \mathrm{~F}_{254^{-}}$ dichloromethane system will not be suitable since their $R_{f}$ is almost the same and resolution will be impossible.

Investigation with silica gel-(1:1) ethyl acetate/chloroform systems gave $R_{f}$ spread of $0.42-0.84$ (Table 4). It is of interest that results obtained for silica gel 60-ethyl acetate are close to those of silica gel 60-(1:1) ethyl acetate/chloroform, however, results obtained for silica gel $60 \mathrm{~F}_{254}$ - ethyl acetate and silica gel $60 \mathrm{~F}_{254}-(1: 1)$ ethyl acetate/chloroform are not comparable. This trend could be assigned to the difference in composition of the silica gel 60 and silica gel $60 \mathrm{~F}_{254}$ adsorbent materials. The difference between the two adsorbents is that the silica gel $60 \mathrm{~F}_{254}$, contains fluorescence material; $F_{254}$ as adsorbent, however, the silica gel 60 does not contain any fluorescence material.

Analysis with aluminium oxide-ethyl acetate system (Table 5) could detect nitrofen, diuron, propanil and carbaryl with $R_{f}$ spread of $0.61-0.76$. The pesticides atrazine, dioxacarb, propoxur and cyper-methrin were not detected. This adsorbent-solvent system is, therefore, not recom-mended for the study of these chemicals, particularly in residue analysis, which involves low concentration. In the case of aluminium oxide-dichloromethane system only nitrofen was detected and even the nitrofen spot was seen one day after developed plate had been sprayed. In all, analysis with aluminium oxide coated plates gave a heavy yellow background with the detection reagent, making visualization of spots difficult.

\section{Conclusion}

From the results presented it can be concluded that the silica-gel 60-ethyl acetate, silica gel $60 \mathrm{~F}_{254^{-}}$ ethyl acetate, silica-gel 60-ethyl acetate/chloroform(1:1), silica gel $60 \mathrm{~F}_{254}$-ethyl acetate/chloroform (1:1) adsorbent-solvent systems, in general, were suitable for analysis of the pesticides as $R_{f}$ values obtained for the pesticides, when these systems were used, were within the stipulated range of 0.40.8, except for cypermethrin, which was not detected at all with the silica-gel 60-ethyl acetate system. Analysis of the pesticides with silica gel 60 , silica gel $60 \mathrm{~F}_{254}$, using dichloromethane as solvent, was found not suitable except for cypermethrin and nitrofen, as $R_{f}$ values obtained were very low, particularly for atrazine, diuron, and propanil. Analysis with aluminium oxide coated plates was found not suitable since heavy yellow background resulted on spraying the developed plates with the detection reagent, therefore, making it impossible to visualize spots.

\section{Acknowledgement}

The authors are very grateful to $\mathrm{Mr} \mathrm{B}$. Q. Modzinuh, and Mr J. Senuh, all of the Chemistry Department of Ghana Atomic Energy Commission, and Evans Ameho, a student on attachment from Accra Poly-technic for their technical assistance.

References

Abbot D. C., Bunting J. A. and Thompson J. (1965). Determination of Organochlorine Pesticides in Water Analyst. 90: 365-377.

Afful S. (2002). Thin layer chromatographic studies on depletion of some herbicides in two soil ecosystems. (MPhil. Thesis.) Department of Chemistry, University of Ghana, Legon, Accra.

Ambrus A. and Their H. P. (1986). Development of thin layer chromatography for analysis of pesticides. Pure Appl. Chem. 58: 1035-1062.

Gerken A., Suglo J. V. and Braun M. (2001). Crop Protection Policy in Ghana for Ministry of Food and Agriculture. Integrated Crop Protection Project, PPRST GTZ, Pokuase/Accra. 162 pp.

Kirchner J. G. (1967). In Reproducibility of $R_{f}$ Values. (E. S. Perry, A. Weissberger, ed.), pp. 195-201. Interscience Publisher, New York.

Ramasamy M. (1969). Determination of pesticide residues soil ecosystem. Analyst 94: 1075-1085.

Ware W. G. (1983). Pesticides - Theory and Application. W. H. Freeman and Company. New York.

West African Journal of Applied Ecology, vol. 14, 2008 
Yeboah P. 0., Lowor S. T. and Akpabli. C. K. (2002). Detection and determination of pesticides using thin layer chromatography. Part 1. Physico-chemical conditions. J. appl. Sci. Technol. 77(1-2): 7-83.

Yeboah P. O., Lowor S. T. and Akpabli. C. K. (2003). Comparison of thin layer chromatograph and gas chromatograph determination of propoxur residues in a cocoa ecosystem Afri. J. Sci. Technol.4: 24-28. 